\title{
Cenelestao
}

\section{Revista Em Questão: 35 anos de história}

\author{
Samile Andrea de Souza Vanz \\ Doutora em Comunicação e Informação; Universidade Federal do Rio Grande do Sul, Porto Alegre, RS, \\ Brasil; \\ samilevanz@terra.com.br
}

\begin{abstract}
Resumo: Para celebrar o aniversário de 35 anos da revista Em Questão em 2021, este artigo apresenta os antecedentes históricos de uma das revistas brasileiras mais antigas e respeitadas na área de Ciência da Informação. O histórico é construído a partir de pesquisa documental de informações nos editoriais publicados desde a primeira edição em 1986. A pesquisa foi realizada na coleção impressa e eletrônica. O texto apresenta um apanhado da história cronológica da revista, os principais acontecimentos que marcaram sua trajetória e, também, fatos e dados atuais que caracterizam a Em Questão nos anos mais recentes.
\end{abstract}

Palavras-chave: Em Questão. História.

\section{Cronologia da revista Em Questão}

A história da revista Em Questão remonta ao ano de 1986, quando foi publicado o primeiro exemplar da Revista de Biblioteconomia \& Comunicação, periódico criado experimentalmente pelos alunos da disciplina de Projeto Experimental em Jornalismo II, coordenada pelos professores Rosa Nívea Pedroso e Rubens Constantino Volpe Weine. Segundo Pedroso e Weine (1986), a intenção do primeiro número da revista era permitir a discussão das tendências teóricas das áreas de Biblioteconomia e Comunicação e servir de espaço para a divulgação de estudos e pesquisas de alunos e professores da Faculdade de Biblioteconomia e Comunicação da Universidade Federal do Rio Grande do Sul (FABICO/UFRGS). Por ser de caráter experimental, não se tinha certeza, no momento da criação do primeiro número, se a permanência do periódico seria viável.

Segundo a professora Rosa Nívea Pedroso (PEDROSO, 2000), editora da revista até a sétima edição em 1996, a primeira edição teve tanta repercussão que a então diretora da FABICO/UFRGS, professora Lourdes Gregol Fagundes da Silva, decidiu torná-la uma publicação da Faculdade e a desvinculou da disciplina de Projeto Experimental em Jornalismo II. O Conselho Editorial, inicialmente 
formado por professores da FABICO/UFRGS, teve professores de outras universidades adicionados na terceira edição, em 1988. O reconhecimento científico foi rápido e o ISSN foi conquistado na quarta edição no ano de 1989. A partir desse momento, a revista passou a receber textos de autores provenientes de diferentes instituições nacionais (PEDROSO, 2000).

Em 1994, a partir da sexta edição, a revista passou a ser patrocinada pelo Programa de Apoio à Editoração de Periódicos da UFRGS (PAEP). O fomento do PAEP permanece até hoje, com a concessão de um bolsista de graduação e o vínculo ao Portal de Periódicos da UFRGS.

A sétima edição da Revista de Biblioteconomia \& Comunicação, em 1996, publicou os primeiros textos internacionais da revista e constituiu o Conselho Editorial Internacional, formado por professores de universidades de Portugal, Colômbia e Uruguai. O editorial do fascículo registrou este importante momento:

\begin{abstract}
Nesta edição, Portugal e México inauguram o caráter internacional da Revista de Biblioteconomia \& Comunicação. Nelson Traquina, da Universidade Nova de Lisboa, analisa a programação televisiva portuguesa e apresenta dados que apoiam a tese da convergência entre produtores públicos e privados. Guillermo Orozco Gomes, da Universidad Iberoamericana do México, analisa os desafios da educação para a recepção neste final de século. E Carmen Rico de Sotelo, da Universidad Católica dei Uruguay, e Ana Maria Lalinde Posadas, da Pontifícia Universidad Javeriana da Colombia, nossas novas integrantes do Conselho Editorial, fortalecem a integração entre os periódicos da Red Iberoamericana de Revistas de Comunicación y Cultura. (APRESENTAÇÃO, 1996, p. 5).
\end{abstract}

A publicação da Revista de Biblioteconomia \& Comunicação foi interrompida, por variados motivos, de 1991 a 1993, em 1995 e de 1997 a 1999. No ano 2000, em comemoração ao aniversário de 30 anos da FABICO/UFRGS, a Revista de Biblioteconomia \& Comunicação voltou a ser publicada. Editada pela professora Jussara Pereira Santos, a edição comemorativa reuniu contribuições de servidores docentes e técnicos administrativos vinculados à FABICO/UFRGS. O número de contribuições foi significativamente alto, o que deu forças para que os empenhos em prol do periódico fossem renovados, com uma edição anual. Mesmo assim, a revista não conseguiu manter a periodicidade e só foi novamente publicada em 2003. 
A Figura 1 apresenta as capas do fascículo 1 de 1986, fascículo 5 publicado em 1990, fascículo 7 e 8 publicados em 1996 e 2000 respectivamente. Tanto o primeiro quanto o segundo fascículo publicaram na capa a lista de artigos do fascículo. A partir do fascículo 3, publicado em 1988, figuras e fotografias começaram a compor as capas da revista.

Figura 1 - Capa dos primeiros volumes da Revista de Biblioteconomia \& Comunicação (nome utilizado até 2000)
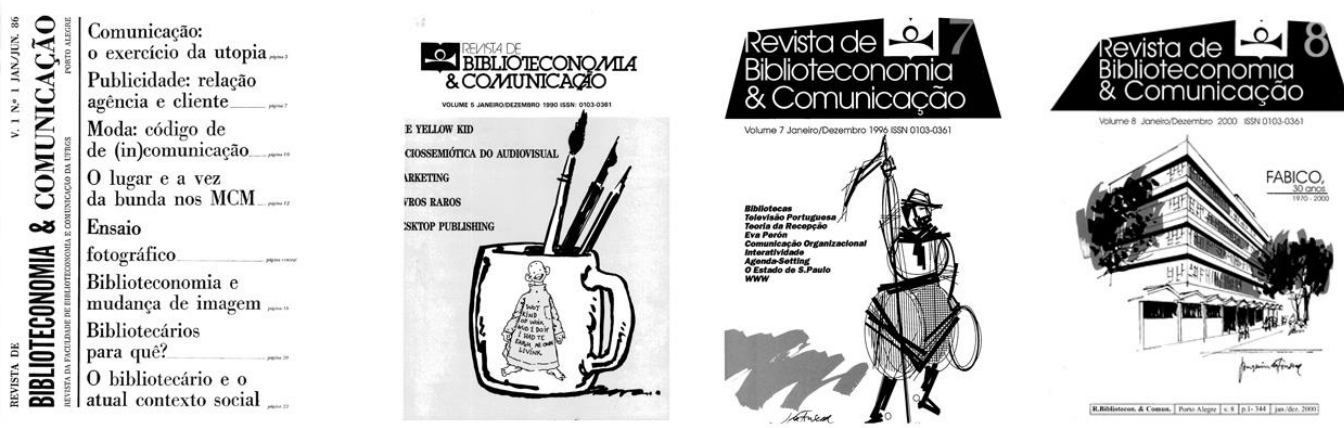

Fonte: Adaptado de Em Questão ([201-?]).

O ano de 2003 marcou profundamente a revista da FABICO/UFRGS. O nome passou por uma grande alteração, passando de Revista de Biblioteconomia \& Comunicação para Em Questão. Ainda sob o comando da professora Jussara Pereira Santos, a periodicidade passou a ser semestral, e os esforços foram direcionados para a divulgação de estudos nas áreas de Informação e Comunicação e campos adjacentes. Outra importante mudança foi o início da publicação eletrônica, a qual permitiu à Em Questão aperfeiçoar recursos e priorizar a visibilidade e acesso ágil ao seu conteúdo.

Em 2003, a partir do volume nove, a revista Em Questão foi espaço para publicação dos resumos de teses e dissertações defendidas no Programa de Pósgraduação em Comunicação e Informação da UFRGS (PPGCOM/UFRGS), e ainda teses e dissertações defendidas por servidores docentes e técnicos da FABICO/UFRGS. O volume 10, de 2004, iniciou a publicação de artigos emanados de trabalhos de conclusão de curso defendidos na FABICO/UFRGS. Com essa iniciativa, a revista pretendeu, por um pequeno período, democratizar 
o acesso dos jovens profissionais ao universo da produção científica, estimulandoos à vida acadêmica, além de publicar os artigos provenientes de trabalhos acadêmicos em caráter de pré-publicação e disponibilizá-los quando fossem aprovados quanto ao mérito e forma (SANTOS, 2004).

A partir do ano de 2005, a equipe editorial da revista passou a ser coordenada pela professora Cida Golin. Foi nessa época que a Em Questão declarou a vontade de seguir rigorosamente os critérios Qualis, estabelecidos pela Coordenação de Aperfeiçoamento de Pessoal de Nível Superior (CAPES), buscando assim o constante aperfeiçoamento e relevância perante a área de interesse (GOLIN, 2005). A nominata dos Conselheiros Científicos cresceu em número e ampliou a abrangência das especialidades.

Em 2006, o periódico passou a utilizar, no âmbito do Portal de Periódicos da UFRGS, o Sistema Eletrônico de Editoração de Revistas (SEER), desenvolvido pelo Public Knowledge Project da Universidade British Columbia. A partir de 2007, foram inseridos na versão 2.0 do sistema todos os seus números (desde 2003). Tal iniciativa foi reflexo do acompanhamento das inovações tecnológicas no escopo da divulgação da produção científica recomendadas pelas agências de fomento. Por meio do SEER, o periódico ganhou rapidez e transparência nos procedimentos editoriais, desde a submissão, avaliação, até a publicação online e indexação. A utilização do protocolo OAI-PMH (Open Archives Iniciative - Protocol of Metadata Harvesting) também possibilita o intercâmbio de metadados, ferramentas de apoio à pesquisa, assim como mecanismos para preservação dos conteúdos.

A adesão ao SEER vinculou a revista ao movimento de Acesso Aberto. Desde então, os autores mantêm os direitos autorais e concedem à revista o direito de primeira publicação, com o material licenciado sob a Licença Creative Commons Attribution (CC BY-NC 3.0), o qual permite o compartilhamento do trabalho com reconhecimento da autoria.

Em 2012, coordenada pelo editor, professor Alexandre Rocha da Silva, a revista Em Questão passou a ser publicada exclusivamente em sua forma eletrônica, objetivando seguir as tendências internacionais para periódicos científicos, otimizar recursos e agilizar a publicação dos conteúdos. Os resultados 
do trabalho desenvolvido pela Comissão Editorial se concretizaram com o conceito Qualis B1 na área de Ciências Sociais Aplicadas no ano de 2012.

Buscando aprimorar a qualidade da revista e alcançar melhores conceitos Qualis (OLIVEIRA; SANTIN; VANZ, 2015) e também a indexação em bases de dados nacionais e internacionais, a Comissão Editorial da revista propôs, ao final de 2013, diversas mudanças. Criou-se uma nova identidade visual, integrando todos os aspectos visuais da revista e um novo projeto gráfico para apresentação dos artigos, com base em referências da Comunicação Científica e do Design Visual (PASSOS; PASSOS; VANZ, 2014). O planejamento gráfico foi adequado ao meio eletrônico, permitindo melhor usabilidade e visibilidade dos textos publicados. A Comissão Editorial disponibilizou aos autores um template específico para publicação digital. Neste ano, a revista alcançou a indexação pela base de dados ProQuest Library Science.

Em continuidade, 2014 também foi um ano chave para a Em Questão: a revista vinculou-se ao Programa de Pós-graduação em Comunicação e Informação (PPGCOM) e passou a publicar somente artigos e resenhas da área da Ciência da Informação. Coordenada pela professora Samile Andrea de Souza Vanz, a Comissão Editorial dedicou esforços para melhorias da usabilidade da revista Em Questão, além da agilização dos processos de recebimento, avaliação e publicação de textos. A equipe editorial foi ampliada a partir da concessão, pela FABICO/UFRGS, de um bolsista do curso de Letras para auxiliar na revisão gramatical dos artigos aprovados.

Em 2015, a revista Em Questão criou a seção Online First, onde são publicados os textos aprovados que aguardam o lançamento de um novo fascículo. Tal seção viabiliza maior agilidade no processo de comunicação científica entre a comunidade da Ciência da Informação. Nesse mesmo ano, a Em Questão passou a ter periodicidade quadrimestral e teve o Digital Object Identifier (DOI) incorporado aos seus artigos, através de convênio com a Associação Brasileira de Editores Científicos (ABEC) e financiamento da FABICO/UFRGS. A maior visibilidade e acesso aos artigos da Em Questão foi obtida em 2016, quando a revista foi incorporada na coleção Redalyc, a Red de Revistas Cientificas de América Latina y el Caribe, España y Portugal. Os artigos 
passaram a receber a marcação XML, conforme padrões adotados pela base de dados indexadora. No final deste mesmo ano, o Qualis A2 para a área de Comunicação e Informação foi conquistado, configurando um novo patamar no reconhecimento da qualidade da Em Questão.

Em agosto de 2017, a revista passou a ser indexada pelo Google Acadêmico e pela Dialnet, base de dados espanhola de Ciências Sociais e Humanidades. No mesmo período, a fim de atender as novas demandas advindas do reconhecimento e visibilidade alcançados, a revista incorporou em sua equipe uma profissional bibliotecária com dedicação exclusiva. $\mathrm{O}$ ano foi marcado também pelo lançamento do plano de marketing da revista, que incluiu entre seus produtos, a página da Em Questão no Facebook.

Atenta às discussões sobre ética na publicação científica, a revista Em Questão incorporou em 2018 as Diretrizes Éticas aos Autores, segundo fluxos de decisão e resolução de conflito da Committee on Publication Ethics (COPE). Em dezembro deste mesmo ano, a indexação na base de dados Emerging Sources Citation Index, produzida pela Clarivate Analytics, foi conquistada. No ano seguinte, para atender a grande demanda de submissões, a Em Questão ampliou o volume de manuscritos publicados a cada edição, de cerca de 15 para 18 documentos. Essa decisão agiliza a publicação definitiva dos textos aprovados pela revisão por pares, publicados na seção Online First tão logo estejam revisados e diagramados pela equipe. A modalidade de publicação foi reafirmada em 2020, quando a equipe editorial decidiu pela não adesão à publicação continuada (VANZ; SILVEIRA, 2020).

Em 2020, a Em Questão incorporou em seus processos editoriais a Declaração de Autoria e Responsabilidade, documento que deve ser assinado pelos autores e disponibilizado no SEER no momento da submissão do manuscrito. Os artigos passaram a ter registro de sua própria referência em uma seção "Como citar", com intuito de facilitar a referenciação pelos leitores.

A comemoração aos 35 anos da revista em 2021 é marcada por profundas transformações. A periodicidade, até então quadrimestral, passa a ser trimestral, conferindo maior agilidade na veiculação dos manuscritos. A revista que era até então publicada pelo Programa de Pós-graduação em Comunicação, passa a ser 
coordenada pelo Programa de Pós-graduação em Ciência da Informação (PPGCIN/UFRGS), aberto em 2018 na FABICO/UFRGS.

Preocupada com a preservação digital de seus conteúdos, a revista Em Questão utiliza o sistema LOCKSS para criar um sistema de arquivo distribuído entre bibliotecas participantes, e permite a essas bibliotecas criar arquivos permanentes da revista para preservação e restauração. A revista também está preservada na Rede Cariniana, com vistas a garantir o acesso continuado a longo prazo dos conteúdos publicados digitalmente.

A periodicidade da Em Questão, inicialmente anual, passou a semestral em 2003, quadrimestral em 2014 e trimestral em 2021.

\section{Equipe Editorial}

Ao longo dos anos, a equipe editorial foi composta por um grupo diversificado e variado, formado por servidores docentes e técnicos da FABICO/UFRGS, bolsistas de graduação e alunos voluntários dos Programas de Pós-graduação. No início, as atividades eram realizadas na sala dos editores, e a biblioteca da FABICO/UFRGS atuava na normalização dos artigos e na gestão e envio das permutas para outras bibliotecas.

Em 2014, quando a revista se vinculou ao Programa de Pós-graduação em Comunicação, ela passou a operar em conjunto com a revista Intexto, já editada pelo mesmo PPG. Juntas, as revistas passaram a ocupar a sala 220 da FABICO/UFRGS e ampliaram a equipe, recebendo da então diretora da Instituição, professora Ana Maria Mielniczuk de Moura, a concessão de duas cotas de bolsa da unidade e o financiamento de uma bibliotecária para assessorar na revisão de normas. Um espaço maior foi conquistado por ocasião do crescimento da equipe, com a conquista de uma bibliotecária para atuar em tempo integral junto às revistas. Em 2018, as revistas Em Questão e Intexto se instalaram na sala 519 da FABICO/UFRGS, onde permanecem até hoje. Ao completar 35 anos, a equipe é formada por um bolsista financiado pelo Programa de Apoio à Editoração de Periódicos da UFRGS (PAEP); por um bolsista de apoio da área de 
Letras concedido pela FABICO/UFRGS para revisão textual; por uma bibliotecária, Natascha Helena Franz Hoppen, além de inúmeros alunos voluntários da graduação em Biblioteconomia e dos Programas de Pós-graduação em Comunicação e em Ciência da Informação.

Os seguintes editores atuaram na revista:

Prof. Dra. Rosa Nívea Pedroso (1986 - 1996)

Prof. Me. Jussara Pereira Santos (2000 - 2004)

Prof. Dra. Cida Golin (2005 - 2009)

Prof. Dr. Valdir José Morigi (2010 -2011)

Prof. Dr. Alexandre Rocha da Silva (2012 - 2013)

Prof. Dra. Samile Andrea de Souza Vanz (2014 - )

\section{Escopo e objetivos}

Atualmente, a Em Questão tem como objetivos:

a) difundir a produção científica de pesquisadores de diferentes regiões do país e do exterior;

b) apresentar eventualmente dossiês temáticos, reunindo a contribuição de especialistas nas suas respectivas áreas.

A revista Em Questão aceita originais em português, espanhol ou inglês e publica exclusivamente textos inéditos, que poderão fazer parte das seguintes categorias:

artigo - apresenta temas ou abordagens científicas originais (relatos de pesquisa, estudos de caso), contribuindo para ampliar o conhecimento até então estabelecido na área; ou de revisão (com análise e discussão de ideias já publicadas, além de métodos, técnicas, processos e resultados);

entrevista - apresenta reflexões de pesquisadores e profissionais de destaque na Ciência da Informação;

resenha - apreciação e análise crítica de obras recém-lançadas. 
A coleção impressa da revista, composta pelo volume 1 de 1986 até o volume 17 de 2011 está disponível na Biblioteca da Faculdade de Biblioteconomia e Comunicação da Universidade Federal do Rio Grande do Sul (FABICO/UFRGS). A partir de 2003, a revista passou a publicar versão eletrônica com o SEER. A coleção antiga está digitalizada e disponível no site da revista, https://cedap.ufrgs.br/jspui/handle/20.500.11959/129.

\section{Edições especiais}

Ao longo de sua história, a Em Questão estabeleceu diversas parcerias e manteve constante publicação de fascículos especiais. O primeiro número especial da revista foi publicado no ano 2010, em comemoração aos 40 anos da FABICO/UFRGS. Organizada pelo editor, professor Valdir José Morigi, o número "Porto Alegre Imaginada" publicou diversos textos científicos sobre a cidade onde a Em Questão é publicada.

O ano de 2021 marca o início de uma parceria longínqua da revista com o Encontro Brasileiro de Bibliometria e Cientometria (EBBC). A terceira edição do evento foi realizada em setembro de 2012, na cidade gaúcha de Gramado, organizada pelo grupo de pesquisa em Comunicação Científica, vinculado ao PPGCOM/UFRGS. A edição especial reuniu os trabalhos apresentados no evento, em uma versão ampliada, incluindo as palestras internacionais. Desde então, a revista Em Questão publicou as edições especiais EBBC nos anos de 2014, 2017 e 2018, organizadas por editores convidados vinculados à Comissão Científica do evento. As capas destas edições especiais refletiram a identidade visual do EBBC.

Em razão da celebração dos 20 anos do PPGCOM/UFRGS, programa de pós-graduação ao qual a revista estava vinculada à época, a Em Questão publicou em 2015 uma edição comemorativa, reunindo artigos de autoria de pesquisadores convidados, entre eles professores do programa, professores visitantes, palestrantes e ex-alunos. A edição especial foi organizada pela própria Comissão Editorial, que utilizou o selo comemorativo do PPGCOM/UFRGS para a capa.

A edição especial de 2019 reuniu trabalhos ampliados provenientes do V Seminário Internacional A Arte da Bibliografia, realizado na Universidade 
Federal de Pernambuco, em Recife, que congregou pesquisadores dedicados à identificação de tendências sobre as questões históricas e contemporâneas da bibliografia. A edição foi organizada pelos editores convidados André Vieira de Freitas Araújo, Giulia Crippa, Gustavo Silva Saldanha e Murilo Artur Araújo da Silveira.

Em 2020, foi publicado o dossiê Patrimônio e Culturas Tradicionais, organizado pelas professoras Dra. Ana Maria Dalla Zen e Dra. Luisa Durán Rocca. A edição especial foi pensada com a finalidade de divulgar estudos sobre as diversas manifestações do patrimônio, que vem sendo objeto de estudos neste século, em diferentes áreas do conhecimento. Dentro da polissemia que o conceito envolve, numa abordagem integral e interdisciplinar, a edição reuniu artigos em torno da análise das relações entre cultura e patrimônio no tempo e no espaço, em todas as suas representações: patrimônio natural, cultural, material e imaterial, bem como patrimônio virtual e científico, e em seus processos de identificação, valoração, registro, intervenção e interpretação. 
Figura 2 - Capa das edições especiais da revista Em Questão
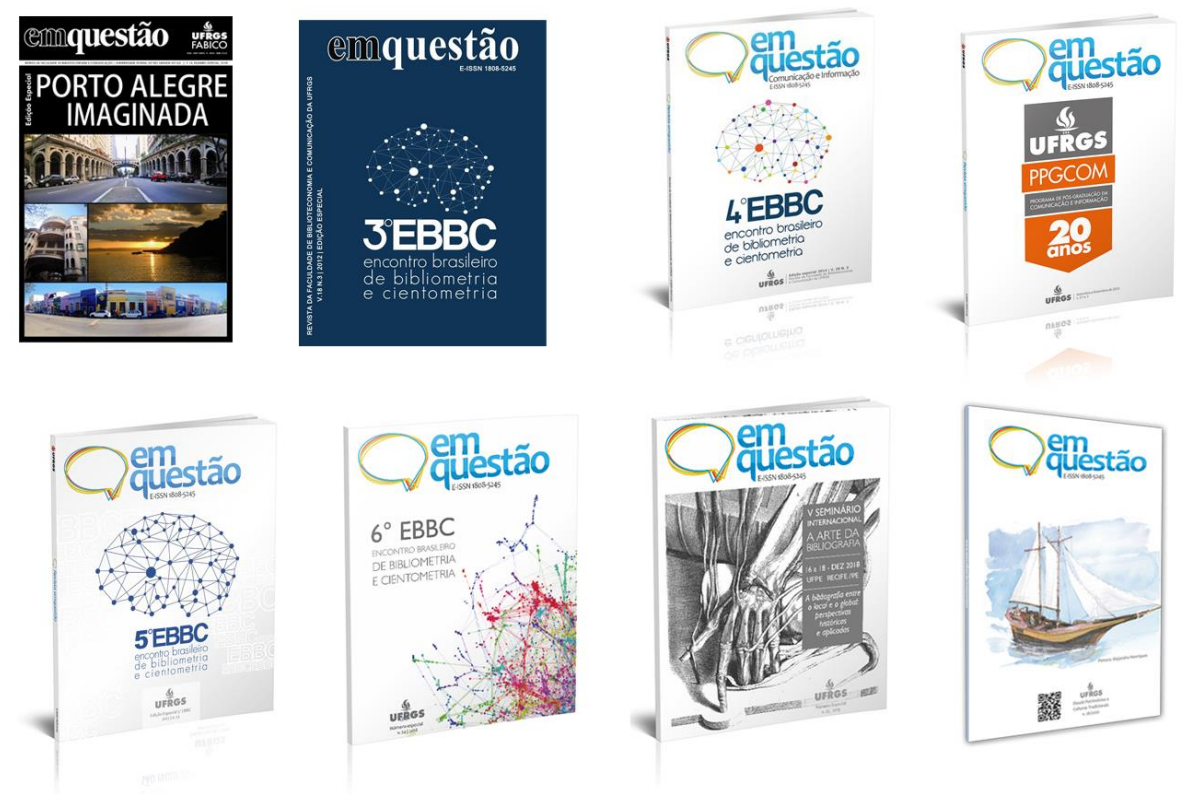

Fonte: Adaptado de Em Questão ([201-?]).

Como se observa na Figura 2, a revista prepara uma capa para cada uma de suas edições. Enquanto as primeiras edições utilizavam desenhos e fotografias, as edições do ano 2000 mantiveram a capa vermelha monocromática. Em seguida, a partir de 2009, optou-se novamente pelas imagens e fotografias. Mais recentemente, a equipe vem desenvolvendo imagens gráficas relacionadas às temáticas abordadas nos artigos.

\section{Submissões e acessos}

A Em Questão entende que as mídias sociais são espaços de aproximação não só entre os periódicos e sua comunidade de autores e leitores, mas também com a sociedade (VANZ, 2018). A página da Em Questão no Facebook é parte estratégica do plano de marketing da revista (https://www.facebook.com/EmQuestao/). Desde sua criação, em 2017, observase o aumento do número de seguidores, comentários e engajamento em geral.

O acompanhamento do desempenho da revista também é feito a partir do Google Analytics, que revela o volume de visitas ao site da revista e países de 
onde os acessos são feitos. Os resultados de tais análises demonstram mais de $80 \%$ dos acessos feitos pelo computador e uma navegação em três páginas a cada sessão de acesso, o que revela que a revista é utilizada para busca de informação (VANZ, 2019). Durante o segundo semestre de 2020, a revista acumulou 39 mil usuários, com sessões que duraram em média 2 minutos. A proveniência dos endereços de IP, apesar de muito variada, é predominantemente brasileira. Os sites do Google Acadêmico, em sua versão americana e brasileira, são os principais canais para atração dos usuários, seguidos do site da Plataforma Lattes CNPq e do Facebook.

\section{Considerações finais}

Este artigo reuniu informações acerca da história da revista Em Questão ao longo de sua trajetória. Em 35 anos de história, a revista, que nasceu como um projeto experimental da disciplina de Jornalismo da Faculdade de Biblioteconomia e Comunicação da UFRGS, cresceu e se transformou em uma respeitada revista da área de Ciência da Informação no Brasil.

Enquanto assiste à profissionalização de muitas equipes editoriais, a Em Questão segue trabalhando "em casa", construída diariamente com o apoio dos docentes, técnicos e alunos da Faculdade. A colaboração voluntária dos alunos de pós-graduação e bolsistas de graduação é fundamental para operacionalizar o processo editorial.

A participação ativa da comunidade brasileira em Ciência da Informação também deve ser mencionada. São inúmeros autores que confiam à revista o resultado de suas pesquisas, submetendo textos em volumes que crescem a cada ano. Além de atuar como autores, colaboram com a revista na avaliação por pares.

Em 2021, o volume 27 da revista Em Questão será festivo. Cada fascículo publicado ao longo do ano divulgará artigos contendo estudos e análises da revista sob diferentes aspectos, tentando registrar esses 35 anos de história.

\section{Referências}

APRESENTAÇÃO. Em Questão, Porto Alegre, v. 7, p. 5, 1996. 
EM QUESTÃO. Edições anteriores. Porto Alegre: Em Questão, [201-?]. Disponível em: https://seer.ufrgs.br/EmQuestao/issue/archive. Acesso em: 4 fev. 2021.

GOLIN, Cida. Apresentação. Em Questão, Porto Alegre, v. 11, n. 1, p. 189$190,2005$.

OLIVEIRA, Caroline; SANTIN, Dirce Maria; VANZ, Samile Andrea de Souza. Revista Em Questão: uma análise da sua trajetória a partir dos critérios Qualis (2003-2012). Em Questão, Porto Alegre, v. 21, n. 1, p. 8-25, jan./abr. 2015.

PASSOS, Jaire Ederson; PASSOS, Paula Caroline Schifino Jardim; VANZ, Samile Andréa de Souza. Projeto de identidade visual para a revista Em Questão. Em Questão, Porto Alegre, v. 20, n. 2, p. 8-27, jul./dez. 2014.

PEDROSO, Rosa Nívea. Um projeto pedagógico se transforma em um projeto científico internacional: uma pequena história da Revista de Biblioteconomia \& Comunicação. Revista de Biblioteconomia \& Comunicação, Porto Alegre, v. 8, p. 291-292, jan./dez. 2000.

PEDROSO, Rosa Nívea; WEINE, Rubens Constantino Volpe. Editorial. Em Questão, Porto Alegre, v. 1, n.1, 1986.

SANTOS, Jussara Pereira. Editorial. Em Questão, Porto Alegre, v. 10, n. 1, 2004.

VANZ, Samile Andréa de Souza. Editorial. Em Questão, Porto Alegre, v. 24, n. 3, set./dez. 2018.

VANZ, Samile Andréa de Souza. Editorial. Em Questão, Porto Alegre, v. 25, n. 2, maio/ago. 2019.

VANZ, Samile Andréa de Souza; SILVEIRA, Lúcia da. Publicação continuada: algumas reflexões. Em Questão, Porto Alegre, v. 26, n. 1, p. 12-16, jan./abr. 2020.

\title{
Scientific journal Em Questão: 35 years of history
}

\begin{abstract}
To celebrate Em Questão 35th anniversary in 2021, this paper presents the historical background of one of the oldest and most respected Brazilian journals in the field of Information Science. The history is built from the documental research of volumes and editorials published since the first edition in 1986. The research was conducted in the printed and electronic collection. The paper presents an overview of the journal's chronological history, the main events
\end{abstract}


that marked its trajectory and also, current facts and data that characterize Em Questão in recent years.

Keywords: Em Questão. History.

Recebido: 03/02/2021

Aceito: $12 / 02 / 2021$

\section{Declaração de autoria}

Concepção e elaboração do estudo: Samile Andrea de Souza Vanz

Coleta de dados: Samile Andrea de Souza Vanz

Análise e discussão de dados: Samile Andrea de Souza Vanz

Redação e revisão do manuscrito: Samile Andrea de Souza Vanz

\section{Como citar}

VANZ, Samile Andrea de Souza. Revista Em Questão: 35 anos de história. Em Questão, Porto Alegre, v. 27, n. 2, p. 12-25, abr./jun. 2021.

Doi: http://dx.doi.org/10.19132/1808-5245272.12-25. 